\title{
What is cognition? angsty monism, permissive pluralism(s), and the future of cognitive science
}

\author{
Cameron Buckner $^{1}$ - Ellen Fridland ${ }^{1}$
}

Published online: 24 July 2017

(C) Springer Science+Business Media B.V. 2017

New sciences often begin with an oversimplified self-conception, defined more by reference to what they aim to supplant than by a deep understanding of the nature of their new subject matter. Cognitive science is no exception; it emerged as a reaction to the radical behaviorism of Watson and Skinner-especially their prohibitions against theorizing about internal psychological states - and generalized ambitiously from a few early successes (Dick 2015; Greenwood 1999). Thus, cognition was conceived of as internal information-processing which somehow went beyond classical and operant conditioning. Specifically, early cognitivists like Chomsky, Newell, and Simon aimed to predict and explain complex forms of high-level behaviors like planning and reasoning by using theoretical and experimental methods that posited computations performed over internal representational states.

However, as sciences mature and nature intervenes in all her glorious and stubborn complexity, these foundational self-conceptions often prove insufficient. Again, cognitive science is no exception. Virtually every aspect of this initial sketch of the nature of cognition and cognitive explanation has now been challenged. In particular, cognitive science now faces at least three areas of open crisis wherein researchers surveying the same data are unable to reach a consensus as to whether the causes of the behaviors observed should count as genuinely 'cognitive': (1) the debate over whether cognition is strictly internal-that is, whether it is brain-bound or extends into the body and environment (Adams and Aizawa 2011; Clark and Chalmers 1998; Menary 2010; Rowlands 2009; Rupert 2009), (2) a crisis in comparative psychology over whether cognition is really mutually-exclusive with association-given that new and more powerful associative models can clear paradigm benchmarks for cognition

\footnotetext{
Cameron Buckner

cjbuckner@uh.edu

1 University of Houston, Houston, TX, USA
} 
(Allen 2006; Buckner 2011, 2015; Dacey 2016; Papineau and Heyes 2006; Smith et al. 2014), and (3) a debate as to whether even "low-level" behaviors might be cognitivegiven recent work revealing a surprising degree of flexibility and control at the level of "automatic" processing (Bargh 1994; Deidrichsen 2007; Fridland 2014, 2017; Logan 1985; Montero 2010; Todorov and Jordan 2002).

These three crises straddle an interrelated tangle of borderline disputes: What exactly does it mean for a cognitive state to be 'internal' to the cognizer, and what are we to make of the intricate forms of interaction between brain, body, and environment that we increasingly find in the performance of tasks which appear to demonstrate cognitive flexibility? Must associative conditioning hypotheses always serve as deflationary alternatives to cognitive hypotheses, or might some associative explanations themselves count as cognitive? Are apparently automated and "mindless" forms of perception, intuition, and skill actually sensitive to conceptual thought, or is their flexibility to be explained away by other means? To be clear, the problem in these disputes is not just that researchers fail to reach consensus on what existing data show; they also often define 'cognition' in different terms, and so disagree about which future experiments would even be relevant to arbitrating their disagreement. Philosophical, methodological, and empirical disagreements are here awkwardly comingled, and even the most fundamental characteristics associated with cognition are potentially up for negotiation. Notably, these problems have led some prominent researchers to suggest that we need to settle on a "mark of the cognitive" before we can make further progress in these debates (Adams 2010; Adams and Aizawa 2011; Rowlands 2009; Walter 2010), while at the same time other researchers have suggested that it is time to give up thinking that 'cognitive' marks out a well-unified psychological category or explanatory methodology at all (Chemero and Silberstein 2008; Dale et al. 2009; Dove 2009; Sullivan 2016).

In the search for a more organized approach to these foundational questions about the nature of cognition, a DFG-funded workshop was organized and hosted at the RuhrUniversity Bochum from June 27-29, 2013. The goal was to bring together leading philosophers of cognitive science to discuss the status of these borderline disputes and especially to consider the task of defining cognition itself. Could clarifying our assumptions about the nature of cognition help, and if so, what methods ought we to adopt to achieve such clarification? Which basic assumptions about the nature of cognitive processing are essential and which dispensable, and why? Are some of the current disputes about characteristics of cognition-for example, whether it must be representational, whether it must be brain-bound, or whether it must be distinct from associative conditioning - distractions from more important issues? Do we need a "mark of the cognitive", and if so, what should it look like, and how would we know if we had it right? Upon the conclusion of an illuminating and successful workshop, we invited the participants to extend their contributions into the articles featured in this special issue of Synthese.

The contributions are organized into three groups of three papers each. The first trio of papers considers the question, "What is cognition?", directly: Do these crises call for a clearer conception of cognition, and if so, what should this strengthened understanding look like to better support empirical work? The second trio of papers propose and advocate for specific methods to achieve a clearer conception of cognition. Finally, 
the third trio of papers consider empirical tensions arising from specific proposals as to the nature of cognition, demonstrating strategies we might adopt to alleviate the tensions generated by nature's pushback. Unsurprisingly, the papers reflect a wide range of disagreement about how best to proceed, but we hope they bring together a variety of concerns and arguments that have not yet made it into print-tending to find expression instead only in those rare moments when philosophers of mind and cognitive scientists poke their head up in existential concern that our subdiscipline is falling into a lot of fruitless talking-past.

The first trio opens with an article by Bill Ramsey ('Must cognition be representational?') offering a series of arguments against defining cognition in terms of representations. Ramsey worries that doing so would prejudge debates about the centrality of representations to cognition that ought to be empirically adjudicated, and might even do harm to our theorizing about representation by forcing us to adopt unduly deflationary accounts to accommodate the trickier cases. He ends by recommending that we seek to characterize cognition in terms of "the kinds of questions we are trying to answer, not by the sort of answers that is on offer." In the next paper ('Arguing about representation'), Mark Rowlands also focuses on the question of whether cognition must be representational, but argues that little turns on either a positive or negative answer to this question, and that the whole representational vs. anti-representational debate has been overblown. His paper reflects on ambiguities and equivocations in theorists' appeals to 'representation', arguing that they have caused representationalists and anti-representationalists to talk past one another in their disputes. Instead, Rowlands argues that there are a range of diverse phenomena that can be considered representational in a variety of different ways, and that the merit of any particular representational claim or assumption should be evaluated on a caseby-case basis. Finally, Colin Allen ('On (not) defining cognition?') argues against the very project of seeking a general characterization of 'cognition', suggesting that even mature sciences need not have a clear idea of their subject matter to proceed fruitfully. Instead, he recommends an attitude of "relaxed" (but not "lazy") pluralism, wherein increased rigor in the particular methods and models deployed in borderline disputes would naturally alleviate the need for increased clarity in general definitions of 'cognition'.

While the first trio of papers are skeptical on the prospects or need for a strengthened understanding of the nature of cognition, the next trio of papers offer novel methodological proposals about how to proceed, possibly opening up new avenues that may preclude this skepticism by avoiding old dead ends. Albert Newen ('What are cognitive processes? An example-based approach') advocates for an example-based approach to characterizing cognition, distinguishing this method from conceptual analysis. We should instead group paradigmatic examples of cognition together and search for deeper principles in their organization, in attempt to see whether 'cognition' forms a natural kind or whether the phenomena studied by cognitive scientists are only unified by convention. He then provides a detailed analysis of how this example-based approach can deal with a specific borderline case from associative learning theory, the comparator hypothesis. In the next paper ('Cognition and behavior'), Ken Aizawa forcefully argues that too much looseness in defining cognition can result in costly mistakes, especially the neglect of old and valuable lessons about the relationship 
between cognition and behavior. Aizawa worries that some of these critiques have been taken so far as to engender confusions between explananda and explanandum that could lead to incoherence, illustrated especially through a case study of cognitive activity in cases of neuromuscular blockade. In the third paper of this trio ('On the proper domain for psychological predicates'), Carrie Figdor proposes a strikingly novel method for better characterizing 'cognition' based in linguistics. Specifically, Figdor suggests that linguistic analysis of the way we use the word 'cognition' shows that some uses of cognitive idioms that skeptics have regarded as metaphoricalthat "neurons prefer, plants decide, and bacteria communicate"-should be a given fully literal interpretation and can usefully contribute to our deeper understanding of cognitive capacities.

The final trio of papers get even further into the weeds, providing up-to-date takes on borderline disputes as they emerge in specific empirical literatures. Hajo Grief ('What is the extension of the extended mind?') begins this section by exploring the way that claims about dynamical coupling have been deployed in arguments for the extended mind hypothesis. In reviewing these arguments, Greif links them to similar moves made in biology that recommend metaphysical extensions of posits like "organism" or "unit of selection"-specifically, environmental constructivism, niche construction, and developmental systems theory-arguing that linking theories of cognitive externalism to biological externalism can provide renewed focus for this debate. In the second paper of the final triumvirate, Ellen Fridland ('Automatically minded') reviews the empirical literature on skill, noting how often a dichotomy between "automatic" and "intelligent" has been misapplied to deny cognitive status to the processes governing skillful behavior. She further extracts a set of features characterizing automaticity, and uses empirical evidence to argue that many processes should be counted as both automatic and cognitive. Finally, John Michael ('Putting unicepts to work: a teleosemantic perspective on the infant mindreading puzzle') closes out the issue by reviewing recent evidence for complex social cognition in infants and young children, noting how a revised proposal of the representational vehicles provided by Ruth Millikan — "unicepts" — can better explain existing data and generate fruitful new questions about the function and developmental trajectory of reasoning about beliefs throughout childhood.

So, with these papers in hand... what is cognition, anyway? Rather than engaging in editorial scorekeeping, we instead recommend some questions to aid digestion of this volume. We hope that the act of bringing these papers together will call more attention to the various flavors of pluralism about cognition and cognitive explanation, and help subject them to more direct criticism. What are the differences amongst the various pluralisms on offer, and how shall we choose between them? Are there limits to pluralistic liberalism that should not be transcended, and what might be the dangers in doing so? Can the more abstract meta-recommendations of the first trio address the needs and concerns of those of the third trio engaged directly in specific borderline disputes, or do they just end up dismissing real empirical disagreements as fruitless talking-past? We look forward to future work on these issues, and hope that even if the present volume raises more questions than it answers, the attempt to address them provides a fruitful step forward along the winding journey to better understanding cognition. 
Acknowledgements The editors thank Albert Newen and Michel Pauen for helping to organize the workshop that set this volume in motion, as well as the DFG for funding it. Buckner would also like to acknowledge the Alexander von Humboldt foundation, which provided him with fellowship support from 2011-2013.

\section{References}

Adams, F. (2010). Why we still need a mark of the cognitive. Cognitive Systems Research, 11(4), 324-331. doi:10.1016/j.cogsys.2010.03.001.

Adams, F., \& Aizawa, K. (2011). The bounds of cognition. Wiley.

Allen, C. (2006). Transitive inference in animals: Reasoning or conditioned associations? In S. Hurley \& M. Nudds (Eds.), Rational Animals, (pp. 175-185). Oxford: Oxford University Press.

Bargh, J. (1994). The four horsemen of automaticity: Awareness, intention, efficiency, and control in social cognition. In R. S. Wyer \& T. K. Srull (Eds.), Handbook of social cognition (Vol. 1, pp. 1-40). Hillsdale, NJ: Erlbaum.

Buckner, C. (2011). Two approaches to the distinction between cognition and "mere association". International Journal of Comparative Psychology, 24(4). Retrieved from http://escholarship.org/uc/item/ $1 \times 28 \times 459$.pdf.

Buckner, C. (2015). A property cluster theory of cognition. Philosophical Psychology, 28(3), 307-336.

Chemero, A., \& Silberstein, M. (2008). After the philosophy of mind: Replacing scholasticism with science. Philosophy of Science, 75(1), 1-27. doi:10.1086/587820.

Clark, A., \& Chalmers, D. (1998). The extended mind. Analysis, 58(1), 7-19.

Dacey, M. (2016). Rethinking associations in psychology. Synthese, 193(12), 3763-3786.

Dale, R., Dietrich, E., \& Chemero, A. (2009). Explanatory pluralism in cognitive science. Cognitive Science, 33(5), 739-742.

Deidrichsen, J. (2007). Optimal task-dependent changes of bimanual feedback control and adaptation. Current Biology, 17, 1675-1679.

Dick, S. (2015). Of models and machines: Implementing bounded rationality. Isis, 106(3), 623-634.

Dove, G. (2009). Beyond perceptual symbols: A call for representational pluralism. Cognition, 110(3), $412-431$.

Fridland, E. (2014). They’ve lost control: Reflections on skill. Synthese, 91(12), 2729-2750.

Fridland, E. (2017). Skill and motor control: Intelligence all the way down. Philosophical Studies, 174(6), 1539-1560.

Greenwood, J. D. (1999). Understanding the "cognitive revolution" in psychology. Journal of the History of the Behavioral Sciences, 35(1), 1-22.

Logan, G. (1985). Skill and automaticity: Relations, implications, and future directions. Canadian Journal of Psychology, 39(2), 367-386.

Menary, R. (2010). The extended mind. MIT Press. Retrieved from https://books.google.com/books?hl=en\& lr=lang_en\&id=DxQNhOS8VjQC\&oi=fnd\&pg=PR7\&dq=extended+mind\&ots=zFVo2CZ-Eh\&sig= o3I5asW0OBaBhGlOfoZhtGBY6vo.

Montero, B. (2010). Does bodily awareness interfere with highly skilled movement? Inquiry, 53(2), 105122.

Papineau, D., \& Heyes, C. (2006). Rational or associative? Imitation in Japanese quail. In S. Hurley \& M. Nudds (Eds.), Compare a journal of comparative education (pp. 187-196). Oxford: Oxford University Press.

Rowlands, M. (2009). Extended cognition and the mark of the cognitive. Philosophical Psychology, 22(1), 1-19. doi:10.1080/09515080802703620.

Rupert, R. D. (2009). Cognitive systems and the extended mind. Oxford University Press. Retrieved from http://books.google.com/books?id=jpZtWfQ6yCgC\&pgis=1.

Smith, J. D., Couchman, J. J., \& Beran, M. J. (2014). Animal metacognition: A tale of two comparative psychologies. Journal of Comparative Psychology, 128(2), 115.

Sullivan, J. A. (2016). Construct stabilization and the unity of the mind-brain sciences. Philosophy of Science, 83, 662-673.

Todorov, E., \& Jordan, M. I. (2002). Optimal feedback control as a theory of motor coordination. Nature Neuroscience, 5(11), 1226-1235.

Walter, S. (2010). Cognitive extension: The parity argument, functionalism, and the mark of the cognitive. Synthese, 177(2), 285-300. 